\title{
THE EMPLOYMENT OF SCHOOL DIAGNOSTICIANS IN MICHIGAN 1
}

\author{
James A. Dunn \\ The University of Michigan
}

In 1949 legislation was passed in the State of Michigan which enabled Michigan school systems of 5,000 pupil population or over, to retain the services of one or more school diagnosticians ${ }^{2}$ to provide the psychological services necessary for the operation of the Special Education Program for the Mentally Handicapped. This program has now been in operation some 14 years.

The purpose of the present study was to investigate the current status of, and administrator attitudes toward, the employment of school diagnosticians in Michigan. To this end, in the Spring of 1963, a brief questionnaire was sent to all superintendents of Michigan school systems of over 5,000 pupil population. Replies were received from all school systems but two. The superintendents, or their representatives, reported that there were 14 doctoral level and 92 masters level diagnosticians serving them. Certification records indicated that six additional persons were employed by the school systems that did not return the questionnaire. This yields a total of 112 persons who are serving as full-time cmployees of local school systems. This does not include the school diagnosticians employed by county boards of education or jointly employed by two or more smaller systems. There are 95 such persons.

The employment of a diagnostician by a given school system is, of course, contingent upon the availability of a certifiable person; but, in general, it is even more contingent upon that system's receiving State reimbursement for that individual's salary. Excluding the city of Detroit, which could theoretically qualify for 33 additional diagnosticians, in 1963 there were 10 Michigan school systems that were understaffed; that is, there were 10 school systems that could legitimately retain fulltime diagnosticians and still receive State reimbursement. The 10 understaffed systems had a total of 15 vacancies. Only seven of the understaffed systems, however, indicated a desire to hire additional personnel.

\footnotetext{
1Based on a report to the State Advisory Committee on the Training of School Diagnosticians.

2The State of Michigan uses the term school diagnostician for the position of psychological examiner or psychometrician. Although some persons prefer the title school psychologist, that term is more appropriately reserved for persons with more extensive training. At present, however, there is no State certification for the upper level of school psychologist.
} 
It is disconcerting to discover that there are a number of school systems not interested in retaining the services of a school diagnostician even though they are eligible to receive State reimbursement. Such a decision on the part of those systems apparently is not a recent one, either. They have, according to their indication, made no attempt to hire psychological staff in over a year. In addition, one of the adequately staffed systems voluntarily indicated that they were dissatisfied with the services provided by their diagnosticians and that they would not replace them when they left.

On the other hand, 24 school systems, or approximately one-half of the school systems of over 5,000 pupil population, said they had tried to hire a diagnostician within the preceding 12 months. Seventeen systems reported success in hiring 19 persons. The seven systems not successful in hiring diagnosticians report nine full-time vacancies still unfilled. (It should be remembered that these figures deal with local school positions only.)

When asked, "What do you consider a fair salary for a young diagnostician with one year's experience?" the salary quoted by the superintendents ranged from $\$ 5,200$ to $\$ 8,700$. Both the median and the modal salaries were in the $\$ 5,400$ to $\$ 5,500$ range. Approximately $75 \%$ of the superintendents quoted $\$ 6,000$ or less as a "fair salary." Ten per cent of the superintendents, however, indicated that they were not interested in hiring diagnosticians with only minimal qualifications. Instead, they were attempting to hire individuals with more extensive training for whom they felt a fair nine months salary would be in the $\$ 8,000$ to $\$ 9,000$ range.

To summarize, judging from the number of school systems that attempted to hire diagnosticians within the past year, the public still appears to be generally interested in the continuation of psychological services within the schools. This seems a valid conclusion in spite of the fact that there are a number of systems that are not interested in such services, even on a reimbursed basis. This latter situation is serious, however, and ought not be ignored, for it represents the attitude of approximately 1 out of every 12 systems eligible to hire diagnosticians under the reimbursement program. Conversely, though, a comparable number of systems are interested in upgrading their present services and are actively seeking especially well-qualified personnel. Both of these attitudes may reflect a basic dissatisfaction with, or disillusionment in, the service they have received to date. In certain cases, the disillusionment may have resulted in a negative reaction with a consequent desire to terminate the unsatisfactory services, whereas, in other cases the disillusionment may have resulted in a stronger resolve to upgrade their programs through a more rigorous selection policy. 
In conclusion, then, it would seem that the employment opportunities for school diagnosticians are still relatively sound. The pattern of those opportunities, however, has shifted somewhat in recent years. Although there are still a number of openings available in the larger school systems, the younger diagnostician could more reasonably look forward to employment at the county level or at the smaller school level where cooperative arrangements have been made between adjacent communities. The more experienced person, however, and especially the person who has conscientiously pursued a program of additional professional study can begin to look forward to an increasing number of opportunities for employment at a higher level of responsibility and at a more attractive salary than has heretofore been available.

\section{READING RETARDATION AND THE SCHOOL DROP-OUT}

Daniel Schreiber, director of Project: Drop-Outs, sponsored by the National Educational Association, had this to say, "To my mind, the greatest factor in school dropouts is reading retardation. . . . Study after study has shown that the average dropout is two years or more retarded in reading. I suggest that we must take a good hard look at the way reading is taught the culturally different." Lack of intelligence is not a major stumbling block, according to the Bureau of Labor statistics which shows that nearly 70 per cent of some 4000 dropouts possessed normal or higher than normal IQ's (from Christian Science Monitor, April 19, 1963). For the latest on the issue, see: The school drop-out and Guidance and the school drop-out. These books, both edited by Schreiber, were published in 1964 by the National Education Association, Washington, D. C. for $\$ 4.00$ and $\$ 2.00$ respectively.

\section{THE IMPORTANGE OF BEING "ELEMENTARY"}

A long-term developmental study conducted at Fels Research Institute (Yellow Springs, Ohio) indicates that the years between age 6 and 10 are the critical period for the development of the desire to master intellectual tasks. Whereas the child's approach to learning and problem-solving during these years is a good indication of the performance he will turn in as an adult, it was found that a child's achievement under the age of 3 had no relationship whatever to his performance as an adult. His achievements as a 3 to 6 year old had but slight bearing on his performance in later years. A significant sidelight of the study was the discovery that the IQ's of children who could be characterized as problem-solving, independent, and competitive tended to increase during the years between age 6 and 10. The IQ's of more passive, emotionally-dependent youngsters remained static or even decreased. (From Today's Child, February, 1964; also, see Sontag, L. W., Baker, C. T., \& Nelson, Virginia L. Mental growth and personality development: a longitudinal study. Monogr. Soc. Res. Child Develpm., 1958, 23, No. 2 (Serial No. $68)$. 